\title{
Gestão escolar pública e a implantação das tecnologias na educação no Colégio Estadual Yvone Pimentel.
}

(Public school management and the implantation of technologies in education at Yvone Pimentel State College.)

\author{
Adriana Kampa \\ Universidad San Lorenzo Paraguay e Ensino Estadual Paraná-Brasil \\ Maria Aparecida Pankievicz \\ Universidad San Lorenzo Paraguay e Ensino Estadual Paraná-Brasil
}

Fecha recepción: 02-07-2018

Páginas 64-78

Fecha aceptación: 30-09-2018

\section{Resumo.}

O uso das novas tecnologias na mediação escolar como um fator preponderante para a melhoria do processo de ensino e aprendizagem no mundo contemporâneo. 0 Objetivo geral buscou analisar a gestão escolar pública e a implantação das tecnologias na educação no Colégio Estadual Yvone Pimentel. Ainda, identificar a ação do gestor educacional frente às novas tecnologias educacionais e como contribuirá para que estes recursos sejam incorporados à prática pedagógica do professor. O estudo pautou-se na abordagem qualitativa do tipo descritivo, o estudo descreve minuciosamente sobre as tecnologias existentes no Colégio Yvone Pimentel, bem como, a forma de aquisição das mesmas. Contudo, pode-se constatar que 0 gestor educacional buscou a inserção das TICs no Colégio Ivone Pimentel, bem como, está propiciando aos alunos e professores uma melhor formação pautada numa educação ampla e também digital.

Palavras-chave: gestores; educação; novas tecnologias; recursos; pedagógico

\section{Abstract.}

The use of new technologies in school mediation as a preponderant factor for the improvement of the teaching and learning process in the contemporary world. The General Objective sought to analyze the public school management and the implantation of the technologies in the education in the Yvone Pimentel State College. Also, to identify the action of the educational manager in face of the new educational technologies and how it will contribute to these resources being incorporated into the pedagogical practice of the teacher. The study was based on the qualitative approach of the descriptive type; the study describes in detail the existing technologies in the Yvone Pimentel College, as well as the way of acquisition of them. However, it can be seen that the educational manager sought the insertion of ICTs in the Yvone Pimentel College, as well as, it is providing students and teachers with a better education based on a broad and digital education.

Keywords: managers; education; new technologies; resources; pedagogical 


\section{1.-Introdução}

O panorama das instituições públicas em geral é extremamente delicado em vários aspectos da infraestrutura física, lógica e funcional, visto que muitas instituições há anos não recebem investimento nestas áreas

Desde a implantação da Lei n $9394 / 96$ depara-se com uma verdadeira revolução na gestão da escola e da figura do gestor escolar, pois inúmeras responsabilidades, competências e habilidades são exigidas em sua atuação administrativa, pedagógica e comunitária, a partir dos princípios de gestão democrática no âmbito da escola pública. O gestor escolar, desde então, passou a gerenciar, coordenar, acompanhar e executar atribuições que anteriormente não ressoavam no âmbito da escola e da comunidade com tal força, tal como se evidencia com o advento da referida lei.

O Objetivo geral da pesquisa é analisar a gestão escolar pública e a implantação de tecnologias na educação no Colégio Estadual Yvone Pimentel.

Os Objetivos específicos da pesquisa são: 1) Identificar a implantação das tecnologias no período de 2010 a 2017 no Colégio Estadual Yvone Pimentel; 2) Identificar os recursos tecnológicos que o Colégio dispõe para os professores trabalhar com os alunos; 3) Identificar as atividades do gestor escolar que favorecem a implantação das tecnologias no Colégio Estadual Yvone Pimentel.

Este artigo busca relatar como a ação do gestor escolar pode ser decisivo na implantação das novas tecnologias educacionais no ambiente escolar, a fim de que se possa determinar qual é influência do gestor educacional junto aos demais membros da escola para a utilização das novas tecnologias educacionais.

Alguns autores que foram usados para a fundamentação teoria da pesquisa são: Almeida (2004); Alvarenga (2012); Libâneo (2004); Machado (1999); Morán (2010); Pereira (2007); Pretto (1996) etc.

Deste modo, as condições de gerenciamento de muitas das escolas públicas são precárias e deficientes. Infraestrutura, profissionais da educação sem capacitação e desestimulados, culminando com estudantes cada vez mais desinteressados pelo modelo de ensino tradicional, mas extremamente inseridos no mundo digital. Neste contexto, a gestão escolar precisa de ações inovadoras diante deste cenário complexo e repleto de divergências com muitos obstáculos. No entanto, reconhecendo essa dificuldade estrutural, a competência de um diretor de escola pode suprir boa parte das deficiências, desde que tenha em mente que precisa agir diretamente para quebrar paradigmas.

É sabido também que o contato com a tecnologia deve ser diário, pois já se encontra incorporada nas empresas, nos bancos, nos comércios, enfim, em vários setores da sociedade moderna. E os educandos já sentem o efeito da sociedade da informação, pois eles "brincam" com a tecnologia, fruto de suas curiosidades e da ausência do "medo" de errar. Portanto, a questão fundamental é como inserir as Tecnologias de 
Informação e Comunicação (TICS) nos estabelecimentos educacionais valorizando 0 currículo, a prática pedagógica e sobrepondo os limites estruturais das instituições de ensino.

A relevância deste artigo se dá devido a necessidade de incorporar as TIC no âmbito escolar como forma de contribui para 0 acesso à informação atualizada e, principalmente, para promover a criação de comunidades colaborativas de aprendizagem que privilegiam a construção do conhecimento, a comunicação, a formação continuada e a gestão articulada entre as áreas administrativa, pedagógica e informacional da escola.

\section{2.-O gestor educacional e as novas tecnologias.}

Quando se fala em tecnologia costuma-se pensar imediatamente em computadores, vídeo, softwares e Internet. Sem dúvida são as mais visíveis e que influenciam profundamente os rumos da educação. Mas, antes, é bom lembrar que o conceito de tecnologia é muito mais abrangente, tendo em vista que se pode entender por tecnologias os meios, os apoios, as ferramentas utilizados para que os educandos aprendam. Para Moran (2010) além disso, a forma como as pessoas se organizam em grupos, em salas, em outros espaços também pode ser entendido como tecnologia.

Por sua vez, Chaves (2008), afirma que tecnologia é tudo aquilo que o ser humano inventa para tornar sua vida mais fácil ou agradável. Tecnologia não é algo que se encontra pronto na natureza, que nasce em árvores ou de animais. Tecnologia é artefato, é coisa que surge primeiro, como ideia e projeto, na mente do ser humano e, depois, é produzida por ele.

Evidencia-se, neste século XXI, o apogeu das novas tecnologias da informação e da comunicação no âmbito da sociedade moderna. Verifica-se que a convergência das inovações da informática, da comunicação e das telecomunicações está presente nos artefatos tecnológicos que variam desde o telefone celular ao computador, capazes de possibilitar aos usuários, o envio e recebimento de mensagens, ouvir a programação da rádio, assistirem vídeos, produzirem fotos e proporcionar ainda a comunicação audiovisual entre sujeitos em diferentes partes do mundo.

Esta oferta crescente de recursos tecnológicos que se está vivendo alterou consideravelmente o comportamento da sociedade brasileira. Verifica-se, assim, que a tecnologia é parte da história na qual há uma dependência total do homem à máquina e à tecnologia para sobreviver, ocasionando um grande impacto dos recursos tecnológicos digitais no mundo atual.

Com isso surge uma crescente preocupação no que tange à possibilidade de democratização das tecnologias digitais e segundo Pereira (2007), surge a inclusão digital, a qual pode ser entendida como um processo em que uma pessoa ou grupo de pessoas passa a participar dos métodos de processamento, transferência e armazenamento de informações que já são do uso e do costume de outro grupo. Tal 
processo possibilita ter os mesmos direitos e os mesmos deveres dos já participantes daquele grupo onde está se incluindo.

Chaves (2008) afirma que a inclusão digital é um processo mediante o qual as pessoas obtêm acesso à tecnologia digital e se capacitam para utilizá-la de modo a promover seus interesses e desenvolver competências que resultem na melhoria da qualidade de sua vida

No entanto, em relação aos educadores, principalmente àqueles com ampla experiência docente, observa-se um verdadeiro "pânico" em desenvolverem atividades com o auxílio de tais artefatos tecnológicos. Segundo Pretto (1996).

[...] não podemos pensar que a pura e simples incorporação destes novos recursos na educação seja garantia imediata de que se está fazendo uma nova educação, uma nova escola, para o futuro [...] vivemos um momento histórico especial, em que surgem novos valores na sociedade.

A tecnologia chegou e atingiu a todos. Hoje se investe em tecnologias telemáticas de alta velocidade para conectar alunos, professores e comunidade ao ensino presencial e também à distância, e o resultado é uma grande expectativa acerca das soluções que as novas tecnologias trarão ao processo ensino-aprendizagem, afirma Moran (2010).

Não obstante os avanços alcançados nos últimos anos com a melhoria no nível dos indicadores educacionais e, principalmente, com o salto obtido na meta de universalização do acesso ao ensino fundamental, muito ainda tem que ser feito para qualificar esse acesso e vencer a tendência histórica de exclusão social do sistema. Contudo, Pereira (2007) assevera que "o universo que envolve a educação, instituições, professores, educadores e alunos, todos estarão sujeitos a mudanças oriundas da convergência digital."

Na sociedade, as novas tecnologias são incorporadas velozmente e neste mundo em que a informação e conhecimento são cada vez mais as principais fontes de transformações da sociedade, torna-se obrigatório utilizar as novas tecnologias na educação.

Moran (2010) aponta que as tecnologias possibilitam inúmeras formas de se chegar ao aluno, conectando o ensino com a vida do aluno, pois, "na sociedade da informação, todos estamos reaprendendo a conhecer, a comunicar-nos, a ensinar; reaprendendo a integrar o humano e o tecnológico: a integrar o individual, o grupal e o social." (Moran, 2010; p. 61).

Percebe-se, assim, que as mídias podem contribuir com a educação escolar embora a escola incorpore desde os seus primórdios, a legitimação da transmissão e construção de conhecimentos científicos instituídos por uma cultura escolar. 
Em muitas situações persistem na escola uma grande desconfiança, morosidade e ausência de incorporação da tecnologia. O motivo abaixo também reforça essa situação:

Crenças pedagógicas, contudo, podem ser alteradas; o desafio é encontrar a forma mais eficiente de obter transformações. Como aponta Libâneo (2004) ao analisar 0 projeto Um Computador por Aluno (UCA), a adequação de professores nascidos e formados em outro momento para atuarem, compreenderem, intervirem e construírem conhecimento no meio digital costuma ser um dos componentes menos considerados nas ações governamentais de promoção do uso das TIC na educação. (Núcleo de Informação e coordenação do Ponto BR, 2016; p. 19).

E, por isso, há a necessidade de se mudar a realidade cada vez mais constante no âmbito das escolar públicas, qual seja: equipamentos tecnológicos ficam "trancados" em laboratórios ou salas e os alunos e professores não têm acesso aos equipamentos. É bem verdade que tal fato decorre, em grande parte, da falta de infraestrutura das escolas na salvaguarda dos equipamentos e também da falta de existência de monitores especializados, a qual poderia ser substituída pelo preparo dos docentes.

Para tentar minimizar esta situação há também a necessidade de participação dos gestores nos cursos de qualificação para o uso das novas tecnologias, no sentido de que possam incentivar a presença da tecnologia no contexto administrativo e pedagógico na escola, ou seja, os gestores precisam participar do processo de inclusão digital ou de alfabetização tecnológica.

Ao gestor escolar cabe a capacidade de planejamento, liderança, iniciativa, de criação de espaços e clima de reflexão e experimentação, pois a gestão escolar consiste num espaço de mobilização da competência e do envolvimento das pessoas coletivamente para que, por sua participação ativa e competente, promovam a realização dos objetivos educacionais.

A gestão participativa busca criar estruturas descentralizadas em que se faz necessário à sobrevivência da escola, em que o relacionamento cooperativo passa a ser uma ferramenta essencial para superar os conflitos internos nos processos de ensino e aprendizagem e as mudanças nas relações do trabalho. A consciência individual e coletiva exige de seus gestores e demais pessoas da escola visão de globalidade, isto é, saber o que sua tarefa significa na totalidade organizacional.

Segundo relatam as autoras Rampelotto et all (2015), ao se viver na era da tecnologia e do acesso à informação, as tecnologias de comunicação e de informação tornam-se ferramentas presentes e que colaboram para que o processo de ensino aprendizagem ocorra de forma dinâmica e colaborativa. É nesta perspectiva de gestão democrática dentro do ambiente escolar que o gestor deve atuar, além de possibilitar e auxiliar na formação contínua do corpo docente. Além disso, o gestor escolar deve atuar de "forma articulada em todas as esferas pedagógica, administrativa, financeira, estimulando a formação continuada. E deve 
levar em consideração a especificidade de cada escola a sua constituição histórica, cultural, social."

Isto porque, como afirma Libâneo (2004), o estudo da organização e gestão da escola tem como objetivos o conhecimento da organização escolar bem como das formas de organização e gestão, competências e procedimentos necessários para atuação de forma eficiente e participativa nas decisões e ações dirigidas ao atendimento dos objetivos educacionais; compreensão das relações entre as orientações gerais do sistema escolas; desenvolvimento de saberes e competências para fazer análises de contextos de trabalho, identificar e solucionar problemas e reinventar práticas diante de situações novas ou inesperadas; capacitação para participação no planejamento, organização e gestão da escola.

Percebe-se, então, que a ação gestora consiste em saber organizar os recursos disponíveis numa visão sistêmica, para viabilizar o objetivo principal da escola, assegurando-lhe qualidade no que faz. Está associada ao fortalecimento da democratização do processo pedagógico, à participação responsável de todos nas decisões necessárias e na sua efetivação mediante um compromisso coletivo com resultados educacionais cada vez mais efetivos e significativos.

E, frise-se, a transformação da escola acontece com maior frequência em situações nas quais diretores e comunidade escolar (funcionários, professores, educandos, pais e comunidade) se envolvem diretamente no trabalho realizado em seu interior.

De acordo com Almeida (2004) o envolvimento dos gestores escolares na articulação dos diferentes segmentos da comunidade escolar, na liderança do processo de inserção das TIC na escola em seus âmbitos administrativo e pedagógico e, ainda, na criação de condições para a formação continuada e em serviço dos seus profissionais, pode contribuir e significativamente para os processos de transformação da escola em um espaço articulador e produtor de conhecimentos compartilhados.

\section{1.-Programas integrados de gestão administrativo-pedagógica.}

O gestor escolar e a sua equipe têm nas tecnologias, hoje, um apoio indispensável ao gerenciamento das atividades administrativas e pedagógicas. O computador começou a ser utilizado primeiro na secretaria para depois chegar à sala de aula. Neste momento há um esforço grande para que esteja em todos os ambientes e de forma cada vez mais integrada, por entender que na escola não se deve separar 0 administrativo e o pedagógico: ambos são necessários.

Numa primeira etapa privilegiou-se o uso do computador para tarefas administrativas, depois cadastro de alunos, folha de pagamento. Depois, os computadores começaram a ser instalados em um laboratório e se criaram algumas atividades em disciplinas isoladas, em implementação de projetos. As redes administrativas e pedagógicas, nesta primeira etapa, estiveram separadas e ainda continuam funcionando em paralelo em muitas escolas. Encontramo-nos, neste momento, no 
começo da integração do administrativo e do pedagógico do ponto de vista tecnológico.

O administrativo está a serviço do pedagógico e ambos têm de estar integrados, de forma que as informações circulem facilmente com as restrições de acesso necessárias, para visualizar qualquer informação que precisarmos checar ou para fazer previsões necessárias.

Imperioso destacar, que a informática educativa está presente no Brasil desde o final da década de 1960, sendo as primeiras ações na área acadêmica da Universidade Federal do Rio de Janeiro (UFRJ) e seu Núcleo de Computação Eletrônica, além do Núcleo de Tecnologia Educacional para a Saúde, o Centro Latino-Americano de Tecnologia Educacional e a Universidade Federal do Rio Grande do Sul (UFRGS).

Em 1983, foi criada, na Secretaria Especial de Informática, a Comissão Especial Informática na Educação e foi aprovado o Projeto Brasileiro de Informática na Educação (Educom), cujo objetivo foi a implantação experimental de centros-piloto em universidades, envolvendo ações integradas com escolas públicas, particularmente as de segundo grau. Na sequência, em 1989, foi criado o Programa Nacional de Informática Educativa (Proninfe) e, em 1997, o Programa Nacional de Informática na Educação (Prolnfo), já na Secretaria de Educação a Distância (SEED) do Ministério da Educação e Cultura. (Núcleo de Informação e Coordenação do Ponto BR, 2016)

Nos últimos anos tem aumentado muito a quantidade da informação e tem havido também grandes avanços na qualidade das informações disponíveis on-line para a comunidade escolar e para o público em geral. Os grandes colégios constroem verdadeiros portais de informação, com áreas dedicadas aos professores, outras aos educandos, aos pais e ao público em geral.

A Internet é um espaço virtual de comunicação e de divulgação. Hoje é necessário que cada escola demonstre para a sociedade, o que ela faz, os projetos que desenvolve, a filosofia pedagógica que segue, as atribuições e responsabilidades de cada um dentro da escola, na divulgação para sociedade de todos os projetos desenvolvidos. Assim se "abre", com possibilidades de acesso para todos em torno de informações gerais.

Cada escola tem uma situação concreta que interfere no processo de gestão com tecnologias. Se atender a uma comunidade de classe alta ou de periferia com os mesmos princípios pedagógicos, terá que adaptar 0 seu projeto de gestão à realidade em que se insere.

Moran (2010) destaca que existe um novo tempo, um novo espaço e outras maneiras de pensar e fazer educação nos dias de hoje na sociedade da informação. O amplo acesso e o amplo uso das novas tecnologias condicionam e reorganiza os currículos as ações da gestão e as metodologias na prática educacional. 
Portanto, na implantação de tecnologias, no ambiente escolar, o primeiro passo é garantir 0 acesso para que as tecnologias cheguem à escola, que estejam fisicamente presentes ou que professores, educandos e comunidade possam estar conectados.

Para isso, o gestor educacional deverá encaminhar à Secretaria de Educação, projetos concisos, que demonstrem a necessidade de a unidade escolar ser informatizada, ou seja, ser contemplada com um Laboratório de Informática Educacional, bem como, com os demais recursos tecnológicos que fazem parte das salas de multimeios.

Como esta é uma ação que depende de recursos diversos o gestor precisa planejar ações diferenciadas que envolvem tanto a mantenedora que é a Secretaria Estadual de Educação como a Associação de Pais e Mestres do colégio. Estas ações garantem que os recursos serão suficientes para a implantação de novas tecnologias na escola.

Na prática acontece a seguinte situação: mesmo ainda distantes do ideal, tem-se avançado nos últimos anos na informatização das escolas. Mas a demanda por novos laboratórios, por conexões mais rápidas, por novos programas é incessante e isso deixa o gestor amedrontado porque não sabe se o investimento vale a pena diante da rapidez com que surgem novas soluções ou atualizações tecnológicas.

O segundo passo na gestão tecnológica é o domínio técnico. É a capacitação para saber usar, é a destreza que se adquire com a prática. Se o professor só toca no computador uma vez por semana demorará muito mais para dominá-lo do que se tivesse um computador sempre à sua disposição.

É como pode se observar na pesquisa realizada pelo Núcleo de Informação e coordenação do Ponto BR. O estudo longitudinal aponta para uma relativa falta de preparo dos atores escolares para o uso das TIC e para a compreensão do papel das tecnologias nas atividades de ensino e aprendizagem na escola. Tal situação está associada ao desconforto e à falta de familiaridade com a tecnologia, evidenciados nas entrevistas realizadas pelo projeto desde 2010. Essa tendência se manteve, em linhas gerais, ao longo do período de 2011 a 2013. (Núcleo de Informação e coordenação do Ponto BR, 2016; p. 79).

O terceiro passo é o do domínio pedagógico e gerencial, realizável com as tecnologias, para facilitar o processo de aprendizagem, permitindo que educandos, professores e pais acessem mais facilmente as informações pertinentes. Nessa etapa costuma-se utilizar as tecnologias como facilitação do que já se fazia antes. $\mathrm{Na}$ prática, por exemplo, tem-se: fazia-se a ficha de cada educando manualmente e agora se adquiriu um programa que automatiza o registro desse educando e 0 acesso a essas informações a qualquer momento. É um avanço, mas ainda se está fazendo as mesmas coisas que antes, só que de uma forma mais fácil. 
O quarto passo seria de buscar soluções inovadoras que sem essas as tecnologias não seria possível. No exemplo anterior, a internet, pode não só facilitar o registro do educando, mas o acesso dos pais às notas dos educandos, a comunicação de educandos de várias escolas do mundo inteiro, a integração telemática dos pais e da comunidade na escola ou da escola em várias comunidades. A integração da gestão administrativa e pedagógica se faz de forma muito mais ampla com os computadores conectados em redes.

As mudanças que invadiram o cenário educacional e, consequentemente, a gestão escolar, desde a formação continuada ganha progressiva importância, como sinal de que 0 aprendizado deve assumir caráter permanente e dinâmico na vida dos profissionais de qualquer organização humana. Segundo Machado (1999) a formação passa a ser vista como instrumento fundamental para o desenvolvimento de competências, envolvendo valores, conhecimentos e habilidades para lidar com as mudanças aceleradas, com contextos complexos, diversos e desiguais, para aprender a compartilhar decisões, lidar com processos de participação e adaptar-se permanentemente às novas circunstâncias e demandas institucionais.

Portanto, a passos lentos a tecnologia começa a adentrar aos espaços educacionais na formação de supervisores e inspetores escolares, na ação contextualizada nas experiências, conhecimentos e práticas. E estes, por sua vez, têm a oportunidade de inserir a tecnologia em sua prática, revendo-a e a reelaborando, colocando essa prática como foco da própria formação.

O educador tem a tarefa de problematizar os conteúdos que a mídia e as tecnologias trazem para o processo de ensino-aprendizagem. "Pela comunicação aberta e confiante desenvolvemos contínuos e inesgotáveis processos de aprofundamento dos níveis de conhecimento pessoal, comunitário e social" (Moran, 2010, p.25). Desta forma, os processos de interação e de comunicação têm papel fundamental na construção do conhecimento.

\section{3.-Metodologia.}

Para o presente artigo optou-se por uma abordagem qualitativa do tipo descritivo. Segundo Alvarenga (2012) a pesquisa qualitativa, pressupõe uma imersão do pesquisador na vida e no contexto, no passado e nas circunstâncias presentes que condicionam 0 problema. Pressupondo, também, uma partilha prática nas experiências e percepções que os sujeitos possuem desde o problema, no intuito de descobrir os fenômenos além de suas aparências imediatas. Para o estudo descritivo o estudo descreve minuciosamente sobre as tecnologias existentes no Colégio Yvone Pimentel, bem como a forma de aquisição das mesmas.

Operacionalização da Pesquisa: dividimos a operacionalização desta pesquisa em duas partes principais: 
$1^{\text {a }}$ Investigação a partir de levantamentos históricos orais e documentais, de como ocorreu o período que antecedeu a implementação das TIC no Colégio Yvone Pimentel, o período durante esse processo;

2a. Investigação de como se deu a implementação das TICs para a aquisição dos recursos tecnológicos no Colégio Yvone Pimentel.

\section{1.-Tempo e lugar.}

O estudo foi um recorte temporal de 2010 até 2017, período da atual gestão. Para a coleta de dados foram realizadas visitas ao Colégio Estadual Yvone Pimentel as quais ocorreram conversas com gestores, agentes educacionais e docentes. 0 pesquisador fez uso da lista de observação para coleta de dados da pesquisa. Os dados estão demostrados e discutidos em forma de tabelas.

\section{4.-Discussão dos resultados.}

O Colégio Estadual Yvone Pimentel desde o ano de 2009, quando se iniciou uma nova gestão educacional, apresentou grandes mudanças em toda a sua estrutura, física, pedagógica, administrativa e institucional.

Neste período existia apenas o sistema educacional Proinfo, o qual, através de recursos federais a Associação de Pais, Mestres e Funcionários (APMF) adquiriu 0 sistema de instalação da estrutura laboratorial.

Tabela 01: Mudanças na estrutura física, pedagógica, administrativa e institucional.

\begin{tabular}{c|l}
\hline \multicolumn{1}{c|}{ Período } & \multicolumn{1}{c}{ Dados da pesquisa } \\
\hline De 2010 a 2015 & $\begin{array}{l}\text { O colégio não adquiriu nenhum programa em específico, apenas } \\
\text { investiu maciçamente em sistema de câmeras para } \\
\text { monitoramento das salas, as quais foram adaptadas na quadra } \\
\text { poliesportivas temporariamente, enquanto todo o colégio } \\
\text { passava por reforma e ampliação. }\end{array}$ \\
\hline De 2013 a 2015 & $\begin{array}{l}\text { Foi feita uma reforma geral no colégio e então se passou a } \\
\text { investir na aquisição das tecnologias, através da iniciativa pública } \\
\text { e privada. }\end{array}$ \\
\hline Após 2015 & $\begin{array}{l}\text { Foram mandados de 600 a 800 e-mails para as empresas } \\
\text { privadas solicitando algum tipo de equipamento, eis que é sabido } \\
\text { que tais empresas necessitam trocar suas tecnologias de forma } \\
\text { regular, principalmente nas universidades. }\end{array}$ \\
\hline
\end{tabular}

Fonte: A própria pesquisa.

Muitos equipamentos que foram doados por empresas no entanto, necessitavam de consertos, os quais foram custeados pela Associação de Pais e Mestres e funcionários.

Tabela 02: Equipamentos de TICs que o Colégio tem atualmente. \begin{tabular}{l|l} 
Quantidades & Equipamentos de TICs que o Colégio tem atualmente \\
\hline
\end{tabular} 


\begin{tabular}{c|l}
\hline 65 & $\begin{array}{l}\text { Dois laboratórios com os computadores já existentes e os doados } \\
\text { pelo SESI e SESC, o primeiro com 40 desktop e o segundo com 25 } \\
\text { desktop; }\end{array}$ \\
\hline 3 & Roteadores com sinal wi-fi em toda a escola, com verba da APMF; \\
\hline 5 & Lousa digital; \\
\hline 16 & Sala multimídia com "isofilm" nas janelas; \\
\hline 20 & Netbooks com intranet para professores \\
\hline 1 & $\begin{array}{l}\text { Projetores com internet tem em todas as salas; } \\
\text { imediatamente vai uma mensagem para o pai com esta } \\
\text { informação); }\end{array}$ \\
\hline 16 & $\begin{array}{l}\text { Todas as salas têm som e câmeras para monitorar (teve } \\
\text { autorização de todos os pais). Com esta tecnologia os alunos não } \\
\text { saem da sala de aula pois a comunicação chega na sala de aula. }\end{array}$ \\
\hline
\end{tabular}

Fonte: A própria pesquisa.

Um dos principais desafios na implementação do Projeto Piloto CONECTADOS no ano de 2016 na escola, foi de que os professores concebessem, em suas práticas pedagógicas, a possibilidade de ensinar utilizando as TDIC.

Portanto, depois do término da reforma iniciou-se com todos os projetos estruturais de redes de: internet, fibra de óptica, rede wi-fi, COPEL, servidor da Paraná digital, aquisição de 30 computadores da doação e parceria com o SESI, SENAC, SESC, Universidade Positivo, integração da rede e Projeto Piloto do (Registro de Classe online), conectados 1.0 (tablete nas escolas) conectados 2.0 (redes de configurações) ampliação de redes e tecnologias instituição de parcerias e trocas de TI com inciativa privada, aquisição de doação de 30 projetores multimídias, instalação de telas retráteis, sistema de som em todas as salas e ambientes do colégio.

Isto quer dizer que a direção buscou parcerias público privadas e conseguiu montar dois laboratórios com os computadores já existentes e os doados pelo SESI e SESC foram adquiridos roteadores com a verba da APMF do colégio transformando todos os ambientes escolares com sinal wi-fi para que os professores e estudantes possam desfrutar das aulas interativas desenvolvidas pelo estabelecimento. Também com a verba da Associação de Pais e Mestres e Funcionários e, Fundo Rotativo Escolar e (PDDE) o colégio conta com mais três projetores afixados nas salas de multimídia e de Projeção e outro que é encaminhado às salas de aula sempre que solicitados.

Todas as salas de aulas equipadas com projetores e TV multimídia, disponibilidade de acesso ao uso de tabletes pelos educandos, dois laboratórios de informática, sala de multimídia; sala de recursos, internet, etc., alcançando assim, o Nível Intermediário nas competências do Guia Edutec.

Com a vinda do Projeto Piloto Conectados e agora com o Conectados 2.0, os docentes tiveram a oportunidade de fazer cursos on-line sobre as novas tecnologias 
educacionais e de como inserir a escola nessa Cultura Digital, dessa forma um primeiro passo foi dado para a motivação dos profissionais em usar essas tecnologias. Com o recebimento dos recursos (tabletes, a melhoria da rede wi-fi, melhoria da infraestrutura das salas de informática, multimídia e, recentemente dos projetores nas salas), os professores passaram a utilizar com frequência as novas tecnologias em suas aulas. Hoje em dia é comum os estudantes terem aulas na sala de informática e na sala de multimídia, para os mais diversos fins: fazer pesquisas, trabalhos em grupo e até mesmo avaliações e questionários on-line. Os educandos passaram a ver que a escola está inserida na Cultura Digital os estimulando a dedicação aos estudos.

O projeto Conectados também possibilitou que cada professor e estudante tivesse uma conta de e-mail @escola, o que favoreceu a comunicação estudante/estudante, professor/estudante, escola/estudante. É possível com esse e-mail criar grupos para desenvolver trabalhos coletivos no Google Drive e Classroom, por exemplo. Muitos professores têm usado os recursos disponíveis na escola para fazer um trabalho diferenciado, estimulando cada vez mais o aprendizado dos educandos.

A escola participa do Projeto Piloto o programa URANIA, fazendo a formação em horários específicos aos professores.

Está sendo implantando, ainda, o net escola, aplicativo para comunicação com a família. Neste programa tem o (SERE) Sistema de Registro Educacional, no qual consta a nota do aluno, todas as ocorrências e demais informações para que a família acompanhe de perto o desenvolvimento e atividades do aluno na escola.

Tabela 03: Outros Recursos tecnológicos que estão sendo implantados no Colégio.

\begin{tabular}{l|l}
\hline \multicolumn{1}{c|}{ Colégio } & \multicolumn{1}{c}{ Redes sociais } \\
\hline Colégio & Blog do colégio: www.ceyvonepimentel.wordpress.com; \\
\cline { 2 - 2 } $\begin{array}{l}\text { Estadual } \\
\text { Yvone }\end{array}$ & Blog do Projeto Piloto Conectados: \\
Pimentel & http://yvonetrabalho.wixsite.com/blogyvonepimentel \\
\cline { 2 - 2 } & Página no Facebook: @ceyvonepimentel. \\
\cline { 2 - 2 } & Atividades no Classroom, Drive, Scracth Day, \\
\hline
\end{tabular}

Fonte: A própria pesquisa.

Do acima exposto se depreende que a gestão da escola, por meio de sua diretora, adquiriu e modernizou as tecnologias no Colégio Yvone Pimentel, através de parcerias público-privadas, além de estimular os professores à utilização de tais tecnologias. Se for depender apenas do que a Secretaria de Educação fornece, a escola não teria alcançado tantas aquisições.

Segundo Núcleo de Informação e coordenação do Ponto BR (2016), dentre as dificuldades de implantação das TICs encontra-se o pouco investimento e principalmente a baixa conexão com a internet, ou seja:

(...) problemas na qualidade dos dispositivos até a dificuldade para a sua manutenção. De maneira geral, as escolas recebem os equipamentos por meio de 
programas oficiais (federais, estaduais ou municipais) de informatização das escolas. Tais programas possibilitaram o acesso das instituições de ensino às TIC, mas nem sempre em conformidade com suas necessidades ou condições de infraestrutura disponíveis, já que essas iniciativas tendem a ter formatos pré-definidos, sem considerar as especificidades das unidades participantes nos programas. (Núcleo de Informação e coordenação do Ponto BR, 2016, p. 31).

A gestão do Colégio Yvone Pimentel vem priorizando a implantação e assessorando 0 desenvolvimento das mesmas nas práticas pedagógicas.

Rampelotto (2015) asseveram que a existência das TICs na escola está acontecendo de forma rápida em virtude da conectividade dos alunos e da realidade social e é papel do gestor estar atento a essas situações e aliá-las ao processo ensinoaprendizagem, pois se verifica que as tecnologias estão presentes na vida dos alunos, às vezes mais do que nas dos professores, tendo em vista que fazem parte da realidade dos aluno para que todos.

Por outro lado, a necessidade de se investir também nos professor já que, como citado acima, às vezes os alunos sabem mais de TICs do que os próprios professores. E este também é um papel decisivo para os gestores ao investir na capacitação de seu corpo docente.

Portanto, toda a equipe pedagógica, administrativa e ambientes do colégio estão totalmente automatizados e utilizando equipamentos para total integração com a educação.

\section{5.-Conclusão.}

Ao explorar as potencialidades das TIC no cotidiano, principalmente 0 acesso à internet, a escola neste caso abriu novas relações para o saber, vivenciando a comunicação compartilhada e a troca de informações com outros espaços do conhecimento que possuem os mesmos interesses. Essa abertura e a articulação com diferentes espaços potencializa a gestão escolar, provocando mudanças substanciais no interior da instituição, nas quais o ensino, a aprendizagem e a gestão participativa se desenvolve em um processo colaborativo com os setores internos e externos da comunidade escolar.

No entanto, isoladamente, as tecnologias não podem gerar mudanças. Sua inserção no cotidiano da escola exige a formação contextualizada de todos os profissionais envolvidos, de forma que sejam capazes de identificar os problemas e as necessidades institucionais, relacionadas à implantação e uso de tecnologias. Assim sendo, com a identificação, segue-se em busca de alternativas que lhes permitam a transformação do fazer profissional, com base em metodologias pautadas em novos paradigmas. Essa formação fortalece as ações da gestão escolar na busca de condições que ajudem a articulação do uso administrativo e pedagógico das tecnologias na escola. 
Senso assim, cabe a formação profissional para que estes sejam capazes de articular e utilizar as novas tecnologias e mídias na sala de aula é papel da universidade; todavia, a formação continuada em serviço deverá ser proporcionada pela escola, ou pelas Secretarias de Educação. É papel do gestor educacional buscar parcerias junto às instituições de ensino superior, buscando formação continuada em serviço para os educadores, para que seja amenizada, ou sanada, esta deficiência na formação do educador.

Contudo, pode se constatar que o gestor educacional conseguiu fazer a inserção das TICs no Colégio Ivone Pimentel, bem como está propiciando aos alunos e professores uma melhor formação pautada numa educação ampla e também digital.

\section{6.-Referências.}

Almeida, M., Rubim, L. (2004). O papel do gestor escolar na incorporação das TIC na escola. Experiências em construção e redes colaborativas de aprendizagem. São Paulo: PUC.

Alvarenga, E.M. (2012). Metodologia da investigação quantitativa e qualitativa. Normas técnicas de apresentação de trabalhos científicos. 2. ed.1.reimp. Versão em Português. Cesar Amarilhas. Asunción: A4 Dissenos.

Chaves, E.O.C. (2008). A inclusão digital e a escola. Recuperado de: http://www.escola2000.org.br/pesquise/texto/textos.

Libâneo, J.C. (2004). Organização e gestão da escola. Teoria e prática. 5.ed. Goiânia: Alternativa.

Machado, M.A.M. (1999). Políticas e práticas integradas de formação de gestores educacionais em Conselho dos Secretários Estaduais de Educação. Gestão educacional tendências e perspectivas. São Paulo: Cenpec.

Ministério da Educação. (1996). Lei de Diretrizes e Bases da Educação. Lei 9.394/96. Brasília: Ministério da Educação e Cultura.

Moran, J.M. (2010). Ensino e aprendizagem inovadores com tecnologias audiovisuais e telemáticas. Em Moran, J.M., Masetto, M.T. y Behrens, M.A. Novas tecnologias e mediação pedagógica. Coleção Papirus Educação. p.1166.ed.12. Campinas: Papirus.

Núcleo de Informação e coordenação do Ponto BR. (2016). Educação e tecnologias no Brasil livro eletrônico. Um estudo de caso longitudinal sobre o uso das tecnologias de informação e comunicação em 12 escolas públicas. Núcleo de Informação e coordenação do Ponto BR. São Paulo: Recuperado de: https://cetic.br/media/docs/publicacoes/7/EstudoSetorialNICbr TIC. 
Pereira, J.T. (2007). Educação e sociedade da informação. Em Coscarelli, C.V., Ribeiro, A.E (Orgs.). Letramento digital. Aspectos sociais e possibilidades pedagógicas. p.13-24. 2.ed. Belo Horizonte: Autêntica.

Pretto, N. L. (1996). Uma escola sem/com futuro. Rio de Janeiro: Papirus.

Rampelotto, E.M., Melara, A. y Linassi, P.S. (2015). Gestão escolar. O uso das tecnologias de informação e comunicação e suas possibilidades. Educere. XII Congresso Nacional de Educação. PUCPR, 26 a 29/10/2015. Recuperado de: http://educere.bruc.com.br/arquivo/pdf2015/19668 10826.pdf. 